\title{
A LITERATURA EM SAÚDE PÚBLICA: O ENSINO DE UM "NOVO OLHAR" SOBRE O PROCESSO SAÚDE-DOENÇA
}

SÁ, L.D.; PALHA, P.F.; VILLA, T.C.S. A literatura em saúde pública: o ensino de um novo olhar sobre o processo saúde-doença. Rev.latino-am.enfermagem, Ribeirão Preto, v. 6, n. 3, p. 55-60, julho 1998.

“...a essência da educação é a natalidade, o fato de que seres nascem para o mundo"

(Hannah Arendt)

Este "paper" apresenta a utilização de obras da Literatura Brasileira em disciplinas vinculadas à área de Enfermagem em Saúde Pública, na Escola de Enfermagem de Ribeirão Preto, da Universidade de São Paulo-EERP/USP. Tem como objetivo o relato preliminar de uma experiência que visa sensibilizar o aluno do Curso da Graduação em Enfermagem, no que concerne a ampliação do "olhar" sobre a realidade, na qual se estabelecem as relações entre os homens e o processo saúde-doença, dentro da concepção de complexidade e singularidade do viver-adoecer humano considerando espaço e tempo. Em fase primária de execução, essa experiência vem se baseando metodologicamente nas concepções da Nova História (École des Analles) no paradigma da da complexidade (MORIN), no conceito de circularidade e do paradigma indiciário (GINZBURG).

UNITERMOS: literatura, saúde pública, ensino

\section{À GUISA DA INTRODUÇÃO}

Enquanto pós-graduandos da Escola de Enfermagem de Ribeirão Preto, Universidade de São Paulo-EERP/USP, buscamos tornar mais dinâmicas as aulas da disciplina Políticas de Saúde. Assim, servimonos das artes - música, cinema, fotografia, e literatura, estabelecendo uma relação interdisciplinar, na perspectiva de ampliar as informações recebidas. Buscávamos, além das obras referenciadas pelo programa, outras fontes, momentos, espaços e história que auxiliassem na compreensão da realidade.

Essa experiência, e mais o conhecimento prévio de que uma colega docente já utilizava a literatura na disciplina de Enfermagem Psiquiátrica da Universidade do Rio Grande do Norte, levou-nos a pensar, enquanto bolsistas/voluntários do Programa de Aperfeiçoamento de Ensino-PAE/USP, numa estratégia de ensinar Enfermagem em Saúde Pública utilizando obras da literatura brasileira, atitude esta acatada pela docente responsável pela disciplina. Passamos juntos a investir na idéia. Tínhamos um problema comum a maioria dos professores da área de Saúde Pública: a manifesta apatia do aluno frente às dimensões da realidade que cercam o processo saúde-doença. Daí a nossa intenção, qual seja, a de introduzir novas abordagens no processo de ensinoaprendizagem nas disciplinas de Enfermagem em Saúde Pública, cujo propósito reside em buscar respostas à seguinte indagação: Considerando a complexidade do processo saúde-doença, como sensibilizar os alunos de Enfermagem, principalmente os que cursam as disciplinas de Saúde Pública, diante de uma realidade que é complexa e ao mesmo tempo singular?

MORIN(1991) define complexidade como sendo,

\footnotetext{
* Enfermeira, professora Assistente junto ao Departamento de Enfermagem de Saúde Pública e Psiquiatria da Universidade Federal da Paraíba. Doutoranda do Programa de Interunidades em Enfermagem, Escola de Enfermagem de Ribeirão Preto, Universidade de São Paulo-EERP/USP

** Enfermeiro, professor Auxiliar junto ao Departamento de Ciências da Saúde da Universidade Regional do Noroeste do Estado do Rio Grande do Sul. Mestrando em Enfermagem em Saúde Pública, Escola de Enfermagem de Ribeirão Preto, Universidade de São Paulo-EERP/USP

*** Enfermeira, professora Assistente Doutora junto ao Departamento de Enfermagem Materno Infantil e Saúde Pública-MISP, da Escola de Enfermagem de Ribeirão Preto, Universidade de São Paulo-EERP/USP
} 
à primeira vista, como um fenômeno quantitativo sujeito à extrema quantidade de interações e interferências entre um número grande de unidades, e que compreende incertezas, indeterminações e fenômenos aleatórios. $\mathrm{Na}$ realidade, estamos falando do paradigma da complexidade que, para CASTIEL (1994),

"trata-se, em linhas gerais, de um modo de pensar relacionado a sistemas elou processos:

a) compostos por uma grande quantidade de elementos, implicando a existência de niveis distintos de organização;

b) nos quais há carência de um corpo conceitual suficiente para abordá-los;

c) com capacidade de desencadear alterações imprevistas nos seus estados, de modo a permitir a emergência de novas propriedades, ao se transitar por diferentes níveis de organização;

d) tal desencadeamento de novas (e inesperadas) formas de integração dar-se-ão mediante processos de recursividade sobre as condições iniciais".

A interface entre o referido paradigma e o processo saúde-doença, concorre para que a compreensão desse último se dê para além de sua especificação e determinação, por enquanto circunscritas a grupos e classes sociais. Portanto, colocando o processo saúde-doença à luz do paradigma da complexidade, vamos considerá-lo complexo e singular, tanto nos grupos e classes, como em cada indivíduo inserido em grupos e/ou classes.

O homem, ao fazer a história, como diz MORAIS (1992), cria, consome e recria a cultura sendo esta tecida num emaranhado de crenças, valores, atitudes, costumes, mentalidades, práticas temporais e "atemporais". É pelo urdir dessa teia, da cultura, que o homem participa da construção da história. Sendo assim, considerando a complexidade das relações que surgem e ressurgem nesse processo de (re)elaboração, concebemos a história sob o pensamento daqueles historiadores que, por três gerações, movimentam a École des Annales****. Autores de uma nova história, compreendem que o processo do viver humano transcende ao entendimento da história restrita a sua conformação no âmbito exclusivo da macroestrutura econômica. Essa história nova foi definida pelo aparecimento de novos problemas, de novos métodos que renovam domínios tradicionais da história (demografia histórica, história religiosa, história social, etc.) e, o que é mais marcante, pelo aparecimento no campo da história de novos objetos, em geral reservados até então à antropologia, a saber, alimentação, corpo, gestos, imagens, livros, mitos, sexo, filme, clima, inconsciente, mentalidade entre outros.
O objetivo dessa nova história, ou melhor, o seu desejo, em LE GOFF (1993), se lê:

"O desejo da história nova de construir uma história do homem total, com seu corpo e sua fisiologia situados na duração social, a preocupação de alguns grandes biólogos com fazer da história de sua ciência um instrumento de pesquisa de uma maneira não externa mas interna e ampliar as suas pesquisas às dimensões da ecologia humana fazendo intervir a história, a geografia, a antropologia, a sociologia, a demografia, juntamente com a biologia propriamente dita, deixou entrever grandes perspectivas ai".

Até o momento, observando os preceitos da formação cartesiana, temos percebido que deixam lacunas quanto à formação profissional como um processo amplo, restringindo portanto o ensino à passagem da informação. Se a ciência está sendo questionada em algumas de suas abordagens, se já não concordamos com a verdade cartesiana, também não nos sentimos, conseqüentemente muito bem em continuar repassando "fórmulas", "receitas" herméticas, ensimesmadas em certezas que já não mais respondem às formas complexas do viver humano. Em outras palavras, carecemos de um projeto pedagógico em saúde, principalmente em Saúde Pública, que ultrapasse os limites do reproduzir conteúdos e práticas. Buscamos, assim, operacionalizar um instrumento que permita ampliar o olhar do aluno acerca da realidade que o cerca, notadamente no que se refere ao processo saúde-doença, determinado não somente por fatores sócio-econômicos, mas permeado pelas singularidades que diferenciam os homens e os aglomerados sócio-culturais, em seus espaços e tempos. Não podemos continuar respaldando um pensamento que, de acordo com ROSSI (1992),

" $A$ realidade humana se divide, prática $e$ teoricamente no campo da ratio, ou seja, no mundo da racionalização, dos meios, da técnica, da eficácia, e no campo dos valores e das significações humanas, que de uma maneira paradoxal tornam-se domínio do irracionalismo."

De alguma maneira, se esse universo humano é plural, e aí se complexificam as formas de viver-adoecermorrer para além da determinação de classes sociais, necessário se faz perceber os aspectos subjetivos dos indivíduos, grupos e sociedade, nesta emaranhada teia de sobrevivência na qual se situa o homem pós-moderno. $\mathrm{O}$ próximo século, que já começou, exige a formação de profissionais, e principalmente profissionais na área de

**** A esse respeito recomendamos BURKE, P. A Escola des Annales, 1929-1989. A revolução francesa da historiografia. São Paulo: Unesp, 1991 
saúde, que, além da competência técnica e política, sejam sensíveis a essa realidade multiplural.

Encontrando respaldo no pensamento de Cox apud SÁ (1995), no momento em que se expressa sobre a formação do Enfermeiro para o século XXI, a autora advoga que a educação em Enfermagem, quer seja no âmbito da graduação, quer seja no âmbito da pósgraduação, além de garantir o conhecimento essencial à uma prática terapêutica, deverá promover as capacidades intelectuais e as competências para a investigação, avaliação crítica do exercício profissional e dos planos de ação política.

Concordamos com a autora e, ao mesmo tempo, buscamos o "como". Ousamos acreditar que essa formação, que vem sendo dada de forma tradicional, tem corroído o "ânimo de luta", ou seja, de "lutar com e por", bem como tem "maquiado" o conceito de CUIDARGERENCIAR as ações que envolvem o processo saúdedoença.

Cansados da apatia provocada pelo ensino "livresco" e acrítico, buscamos elaborar um instrumento que possa ampliar o olhar do aluno do Curso de Graduação em Enfermagem e, neste sentido, referendamos as palavras de CALAMÉ (1995), quando afirma ser necessário

"Construir um humanismo do século XXI que não dissocie o sentido e o saber, que saiba que a criatividade sempre surge onde não é esperada, da união de disciplinas e de pontos de vista diversos; que reconheça que os nossos sistemas são sistemas sociotécnicos que associam fatos humanos e dispositivos técnicos, e devem ser abordados enquanto tais; que não separem o corpo da mente; que reconheçam e respeitem a unidade dos homens mais que a coleção de seus órgãos, as unidades culturais mais do que a coleção de seus componentes."

Ancoramo-nos na arte para tentar empreender uma estratégia que venha colaborar para o humanismo do século XXI. Escolhemos a arte, pois como dizia Nietzsche "Resta-nos a arte para não morrermos de verdade".

\section{A ARTE COMO INSTRUMENTO PEDAGÓGICO}

Diante da verdade cartesiana colocamos a arte. Embora não dispondo de muitos elementos para falar da mais importante forma de criar, apostamos que seja uma das mais fecundas fontes de ensinar-aprender-sensibilizarinformar-formar. Pelo visto, maneiras de ensinar utilizando a arte já foram praticadas e pensadas pelos homens dentro de alguns momentos da história. Apontamos os caçadores primitivos, tidos por GINZBURG (1990) como os primeiros historiadores, que recorriam à oralidade, bem como aos desenhos, para ilustrar os comportamentos da fauna e da flora e suas interferências sobre o cotidiano. Eles apresentavam os indícios como forma de ensinar e aprender a sobreviver. Num outro momento da história, quando a Reforma pretendeu ultrapassar os limites da esfera religiosa, YATES(1972), ao escrever sobre a filosofia rosacruciana que surgiu na Europa do século XVII, que estabelecia princípios de harmonia entre microcosmo (homem) e macrocosmo (universo), menciona uma cidade chamada de Cristianápolis, descrita por De Andrea, um dos divulgadores desse movimento

"Enquanto na cidade reina uma extraordinária piedade, e sua vida social é cuidadosamente organizada num plano de devoção, a sua cultura é predominante científica. (...) 'Seus artesões são quase todos homens perfeitamente educados, e isto estimula o progresso inventivo'.(...) O ensino e o estudo são facilitados por todas as partes mediante quadros. (...) Nos laboratórios de história natural os fenômenos dessa matéria estão pintados nas paredes, vendo-se representações de animais, peixes gemas e assim por diante. A pintura como arte, é ensinada e aprendida com devoção."

Essa cidade apresenta também o teatro como forma de adestrar a mocidade, instruir o povo, aguçar a mente, deleitar os velhos, retratar as mulheres e divertir os pobres.

Assim é que compreendemos a grandeza da arte enquanto instrumento que amplia visões sobre "os mundos", pois segundo o pensamento de CAMUS "Se o mundo fosse claro, a arte não existiria". E é CAMUS (1942) que, ao questionar a verdade da ciência, põe a nu os seus limites. Observemos:

“ (...) Tanto na psicologia como na lógica, há verdades mas não há verdade. $O$ 'conhece-te a ti próprio' de Sócrates tem tanto valor como o 'sê virtuoso' de nossos confessionários. Revelam nostalgia ao mesmo tempo que a ignorância. São jogos estéreis sobre grandes problemas. Só são legítimos na medida exacta em que são aproximativos.

Eis umas árvores e eu conheço-lhes a rugosidade, eis a água e eu conheço-lhes o sabor. Estes perfumes de erva e de estrelas, a noite, certas tardes em que o coração se dilata, como negar esse mundo cujo poder e cujas forças experimento? No entanto, toda a ciência dessa terra não me dará nada que possa certificar-me que este mundo é meu. As pessoas descrevem-no e ensinam-me a classificá-lo. Enumeram as suas leis e eu, na minha sede de saber, consinto que 
elas sejam autênticas. Demonstram o seu mecanismo e a minha esperança aumenta. Por fim ensinam-me que este universo prestigioso e matizado se reduz ao átomo e que o próprio se reduz ao electrão. Tudo isso é bom e eu espero que continuem. Mas falam-me de um invisivel sistema planetário onde os electrões gravitam ao redor de um núcleo. Explicam-me este mundo como uma imagem. Reconheço então que os homens se embrenharam pela poesia: jamais 'conhecerei' nada disso. Terei sequer tempo de me indignar? Já mudaram de teoria. Assim, essa ciência que devia ensinar-me tudo, acaba na hipótese, essa lucidez cai na metáfora, essa incerteza resolve-se em obra de arte."

Mas sabemos nós que a arte se apresenta vestida de várias maneiras: em cores e nuanças, em sons e tons, em máscaras, em formas, em outras tantas formas inclusive por meio de palavras.

\section{A LITERATURA E O ENSINO DE UM "NOVO OLHAR" SOBRE O PROCESSO SAÚDE - DOENÇA}

Entendemos que a literatura é a forma de "fotografar", com as lentes da ficção a história feita pelo homem ao empreender a satisfação de necessidades e mais a perseguição de desejos dentro de espaços e tempos. É a arte expressa pelas palavras, oral ou escrita, na forma de prosa e poesia.

A literatura, enquanto arte de pensar um instrumento na área de Saúde Pública, permite-nos descobrir que, para além de perceber o homem no processo saúde-doença e nas nuanças das necessidades preconizadas pela cientificidade, é possível transcender essa apologia. Segundo MORAIS (1992) "O homem é uma criatura de desejo e não de necessidades." Nessa relação ambígua entre desejo e necessidade acreditamos que a segunda, quando satisfeita, vem responder apenas um dogma imposto pelo pensamento cartesiano que fundamenta a atual produção do saber. Assim como o Rei Lear (Shakespeare), acreditamos que, se apenas concedermos ao homem o que necessita ele não passará de um animal.

É contra a condição neo-naturalista do homem que pretendemos proporcionar ao aluno mais do que aquilo que a "ciência normal" determina, ou seja a informação. Fazemos isso com o intuito de que o aluno, na condição de graduando ou de profisssional, não repasse à população, também, o que ela apenas necessita. Procuramos portanto, torná-lo sensível aos problemas sociais, aos desejos e as necessidades das populações e partícipes do exercício da cidadania. Como sabemos uma das mais sérias crises que enfrentamos no momento, reside firmemente, na reduzida participação dos indivíduos em lutar pelos seus direitos de cidadãos, problema esse aqui, bem colocado, pelas palavras de um pequeno agricultor "...o grande problema que nóis sentimos hoje (...), não é só no campo...é nos bairros, a nossa população perdeu a perspectiva. Ela não tem mais ânimo de luta, entende?"*****

Saúde é necessidade, e sua conquista se faz através da perseguição de desejos, de luta, da capacidade de elaborar planos de ação política, ou seja, de ter ânimo para arquitetar qualidades de vida. Insistimos na necessidade de uma nova perspectiva de formação, pois, concordamos com CASTIEL (1994), que o processo saúde-doença passa pelo veio da complexidade e da singularidade do viver humano. Concordamos com ele também quanto ao fato de que é "imperiosa a busca de modelos conceituais e metodológicos que permitam intervenções mais efetivas do que as predominantes nos dias de hoje". Tentemos, pois, "uma intervenção mais efetiva". Respeitando o paradigma da complexidade, bem como o desejo de uma nova história em buscar e fazer a história do homem total, tentemos uma forma mais efetiva de alcançar novos modelos conceituais e metodológicos em Saúde Pública. Desta maneira, entendemos que os homens fazem a história de forma interdisciplinar e, enquanto sujeitos totais, movimentam-se dialeticamente, criando consumindo e recriando sua cultura, sua história.

Essas relações interdisciplinares de elaboração e reelaboração podem ser entendidas dentro do conceito de circularidade. Sobre este, GINZBURG (1995) fala que Rabelais já o utilizava para explicar que "entre a cultura das classes dominantes e das classes subalternas existiu na Europa pré-industrial um relacionamento circular feito de influências recíprocras que se movia de baixo para cima e de cima para baixo". Assim, percebemos que a continuidade das culturas subalternas e dominantes não se dá de formas autônomas per se. Elas se mesclam e se transformam, dialeticamente.

Tentar possibilidades que devolvam o ânimo, significa investir na capacidade criadora do indivíduo, ou seja, entender essa capacidade conforme o pensamento de Einstein sobre a educação, qual seja, o de "Dar um sentido de vida". Dar um sentido de vida ao ser que se educa é o princípio fundamental da verdadeira educação; ou, como dizia outro grande Albert, Albert Schweitez apud MONTEIRO (1988)

"A ética de respeito à vida (...) não admite que um homem seja condenado ou quiçá premiado de viver livre das responsabilidades que impõe a dedicação de um ser humano ao outro. Exige 
que todos nós sejamos, sobre algum aspecto, $e$ em determinado lugar, homens a serviço de outros homens"

Formar, educar, nesta perspectiva, significa combater o arrivismo que segundo CAMPOS (1991) "É a mais importante 'doença social' desse fim de século".

Para além do formar cotidiano, é necessário procurar novas perspectivas de aprimorar o modo de olhar esse homem, buscando na literatura indícios que venham retratá-lo na sua historicidade, enquanto sujeito pertencente a um corpo social. A literatura permite um vasculhar das subjetividades que acompanham o "ser" no seu espaço e tempo. Esse saber apreendido pelo processo de vasculhamento é observado no pensamento de GINZBURG (1990) quando nos diz que “... o que caracteriza esse saber é a capacidade de, a partir de dados aparentemente negligenciáveis, remontar uma realidade complexa não experimentável diretamente ....”. É algo semelhante à realização de leitura de palimpsestos, definidos por ALVES (1995) como

“(...) velhos pergaminhos de couro, quando o texto escrito não mais interessava, as palavras eram lixadas e condenadas ao esquecimento da invisibilidade, e depois alizados em marfim, e sobre a virgindade assim restaurada sobre outra se escrevia. E assim se fazia sucessivas vezes. Chamando-se palimpsestos."

\section{A EXPERIÊNCIA EM PRÁTICA}

No segundo semestre letivo do ano de 1995 e no primeiro semestre de 1996, iniciamos na Escola de Enfermagem de Ribeirão Preto uma experiência, que consistiu na utilização de obras da literatura brasileira em disciplinas vinculadas à área de Enfermagem em Saúde Pública. Empiricamente, investimos na arte como um instrumento capaz de reconstituir a sensibilidade, de ampliar a visão sobre a realidade, possibilitar e potencializar a capacidade do aluno quanto a produção de um saber não dissociado da realidade, da história.

Com os alunos concluintes do curso de Enfermagem, que cursavam a disciplina Administração de Enfermagem em Unidade de Saúde Pública, utilizamos a obra INOCÊNCIA de Visconde de TAUNAY (1990). Romance regionalista, escrito no final do século XIX, essa obra permitiu trabalhar o "olhar" epidemiológico, uma vez que a narrativa é rica em fenômenos ligados ao processo saúde-doença. Com os alunos do primeiro ano do curso de Enfermagem, trabalhamos, na disciplina Introdução à Saúde Pública e Saúde da Comunidade, o livro O CORTIÇO, romance naturalista de Aluisio de AZEVEDO (1991), que foi utilizado para lapidar o "olhar" do aluno sobre o território onde vivem os homens e as relações por eles travadas nesse espaço. Pudemos perceber portanto, a viablidade de se trabalhar, com o uso da literatura, dois importantes fenômenos da saúde coletiva: a epidemiologia e o gerenciamento das ações e serviços de saúde, em um dado território.

De início, solicitamos a leitura das obras indicadas. Nos programas das disciplinas, foi agendado um encontro destinados a discussão das obras. O momento discussivo envolveu dois momentos: o primeiro, se fez pelo emprego de um roteiro previamente elaborado e, só entregue aos alunos, no momento da discussão; o segundo, consistiu em levar o aluno a apontar, nos trechos da narrativa, aspectos relacionados ao processo saúdedoença. Denominamos garimpagem do texto a ação de levar o aluno a mergulhar na narrativa para captar elementos ligados saúde e a doença dos personagens envolvidos. O termo garimpar, já utilizado anteriormente por GINZBURG (1990), assemelha-se a leitura de palimpsestos ou seja, a ... maneira de fazer aparecer de novo aquilo que se escreveu e se apagou. No nosso caso, significa, também, ler nas entrelinhas, buscar a realidade que se esconde entre as palavras.

Uma vez realizado o processo de discussão, solicitamos aos alunos, a avaliação da estratégia empregada, de forma oral e escrita. Por unanimidade, ambas as turmas, consideraram a experiência positiva, a ponto de sugerirem, inclusive, a leitura de títulos literários. Por ocasião da avaliação oral, algumas falas foram expressivas: É importante isso que vocês fazem. Porque o professor primário, ele tem formação pedagógica para ensinar, e o professor universitário ele é treinado para ensinar?" Ao perguntarmos como fariam a releitura de uma das obras, responderam: " Prestando mais atenção nos detalhes".

\section{ALGUMAS PALAVRAS FINAIS}

O fato de não apresentarmos resultados mais detalhados, significa que neste momento o nosso propósito é a de apresentar a experiência. Lembramos que estamos apenas começando. Pelo que temos visto em sala de aula, essa experiência que ora vivenciamos, vem se tornando um instrumento capaz de ampliar "o olhar" do aluno sobre a realidade que o cerca, enriquecendo-se assim de elementos significativos à compreensão do processo saúde-doença além da esfera de classes sociais e da economia. Vale ressaltar que essa estratégia tem a pretensão de se tornar um instrumento decisivo de transformação, no momento em que associa, leituras e realidades. Neste sentido, para finalizar, citamos Mário Quintana

\footnotetext{
"Não pense compreender a vida nos autores. Nenhum disto é capaz Mas, à medida que vivendo fores, melhor os compreendará"
} 
THE BRAZILIAN LITERATURE IN PUBLIC HEALTH: THE TEACHING OF A "NEW LOOK" ABOUT THE HEALTH-ILLNESS PROCESS

This paper presents the use of Brazilian literature in public health nursing courses at the University of São Paulo at Ribeirão Preto College of Nursing.The goal is a preliminary report about experiences that intend to keep the students in touch in order to wide their view of reality, in which relationships between the men and health-illness process are established in the complexity and singularity of human being (ill and life) in each place and time. In the first stage, this experience is based on New History conceptual framework (Écolle des Annale), in the complexity's paradigm (MORIN) and circularity concept and sign's paradigm (GINZBURG).

KEY WORDS: literature, public health, teaching

\section{LITERATURA EN SALUD PÚBLICA: ENSEÑANZA DE UNA NUEVA VISIÓN SOBRE EL PROCESO SALUD-ENFERMEDAD}

Este artículo presenta el uso da Literatura Brasileña en las disciplinas del área de Enfermería en Salud Pública, en la Escuela de Enfermería de Ribeirão Preto de la Universidad de São Paulo-EERP/USP. Su objetivo es relatar en forma preliminar, una experiencia que sensibiliza el aluno de curso de pregrado de Enfermería con respecto a ampliar su visión de la realidad, en donde se establecen las relaciones entre las personas y el proceso salud-enfermedad, dentro de una concepción de complexidad y singularidad del vivir y enfermar del ser human, cosiderando espacio y tiempo. En su fase primaria de ejecución, esta experiencia se basó, metodológicamente en las concepciones de la nueva historia (Écolle des Annales), en el paradigma de la complejidad (MORIN), en el concepto de circularidad y el paradigma indiciário (GINZBURG).

TÉRMINOS CLAVES: literatura, salud pública, enseñanza

\section{REFERÊNCIAS BIBLIOGRÁFICAS}

01. AlVES, R. O quarto do mistério. São Paulo: Papirus, 1995.

02. AZEVEDO, A. O cortiço. São Paulo: Moderna, 1991.

03. BURKE, P. A Escola dos Annalles, 1929-1989. A revolução francesa da historiografia. São Paulo: Unesp, 1991.

04. CALAMÉ, P. Defesa de uma redistribuição de saberes. In: WITKOWSKI, N. Ciência e tecnologia hoje. São Paulo: Ensaio, 1995.

05. CAMPOS, G.W.S. A saúde pública e a defesa da vida. São Paulo: Hucitec, 1991.

06. CAMUS, A. Le mythe de Sisyphe. Paris: Galimard, 1942.

07. CASTIEL, D. O buraco e o avestruz: a singularidade do adoecer humano. São Paulo: Papirus, 1994.

08. GINZBURG, C. Mitos, emblemas e sinais: morfologia e história. São Paulo: Companhia das Letras, 1990.

09. O queijo e os vermes. O cotidiano e as idéias de um moleiro perseguido pela Inquisição. São Paulo: Companhia das Letras, 1995.
10. LE GOFF, J. A história nova. 2. ed. São Paulo: Martins Fontes, 1993.

11. MONTEIRO, I. Enstein: reflexões filosóficas. 3. ed. São Paulo: Martin Claret, 1988.

12. MORAIS, R. Estudos de filosofia da cultura. São Paulo: Loyola, 1992.

13. MORIN, E. Introdução ao pensamento complexo. Lisboa: Instituto Piaget, 1991.

14. PALHA, P.F. O movimento social rural pela saúde em Ijuí-RS. Ribeirão Preto, 1996. Projeto de Dissertação (Mestrado) - Escola de Enfermagem de Ribeirão Preto, Universidade de São Paulo. (mimeo).

15. ROSSI, P. A ciência e a filosofia dos modernos. São Paulo: Unesp,1992.

16. SÁ, L.D. E a enfermagem no século XXI? /Trabalho apresentado no $\mathbf{4 7}$ Congresso de Enfermagem. Goiânia-GO, 1995/. (mimeo).

17. TAUNAY, V. Inocência. São Paulo: Moderna, 1990. 18. YATES, F.A. O iluminismo Rosa Cruz. São Paulo: Cultrix-Pensamento, 1972. 